\title{
Congenital Cytomegalovirus Infection Presenting as Severe Conjugated Hyperbilirubinemia on First Day of Life
}

\author{
Aaradhana Singh* and Ravi Sachan
}

Assistant Professor, Department of Pediatrics, University College of Medical Sciences \& Guru Tegh

Bahadur Hospital, Delhi, India

*Corresponding author: Dr. Aaradhana Singh, MD, Assistant Professor, Department of Pediatrics, University College of Medical Sciences \& Guru Tegh Bahadur Hospital, 155A, F Pocket, GTB Enclave, Dilshad Garden, Delhi-95, India, Tel: 9792390940,E-mail: draaradhanasingh@gmail.com

\begin{abstract}
Congenital Cytomegalovirus infection (CMV) has varied presentations ranging from asymptomatic to involvement of multiple organ systems like central nervous system, gastrointestinal, hepatic and hematopoietic. Jaundice is a manifestation of congenital CMV presenting as neonatal hepatitis or cholestatic jaundice. We report a case of severe conjugated hyperbilirubinemia presenting on the first day of life that was diagnosed as a case of congenital CMV on further workup. Despite intensive phototherapy and exchange blood transfusion serum bilirubin level remained high. So, the patient was started on ganciclovir following which serum bilirubin started falling. Patient was screened for neurological involvement by cranial ultrasound, ophthalmological evaluation and hearing assessment which came out to be normal. Patient was discharged on oral valganciclovir for next 3 weeks. Patient remained developmentally normal during follow up with normal liver function test and blood counts. We report this case as congenital CMV presenting as conjugated hyperbilirubinemia with such high levels of serum bilirubin on first day of life have rarely been reported.
\end{abstract}

\section{Keywords}

Congenital, Cytomegalovirus, Conjugated hyperbilirubinemia, Ganciclovir

\section{Introduction}

Cytomegalovirus (CMV) infection in infants may be acquired prenatally or perinatally. CMV infection is acquired prenatally through transplacental transfer of virus from mother to fetus and is called congenital CMV. Its incidence is $0.15-2 \%$ in developed countries whereas in developing countries $80-90 \%$ of women in reproductive age group are CMV IgG positive [1]. Around $90 \%$ of congenital CMV infections are asymptomatic and $10 \%$ are symptomatic with various clinical manifestations like intrauterine growth retardation, prematurity, chorioretinitis, intracranial calcifications, microcephaly, pneumonia, thrombocytopenia, hepatosplenomegaly, hepatitis and cholestatic jaundice [2,3]. Most of the cases of jaundice in congenital CMV start as physiological jaundice with progressive increase in conjugated component and persist beyond 14 days of life thus being labeled as cholestatic jaundice [3]. Few case reports have mentioned jaundice appearing on first day life as conjugated jaundice [4]. Farhat AS, et al. reported a neonate with total serum bilirubin: $12.8 \mathrm{mg} / \mathrm{dl}$, direct bilirubin: $9.7 \mathrm{mg} / \mathrm{dl}$ [4]. Nazmuddin, et al. reported an infant at 2 months of life with total bilirubin of $23.6 \mathrm{mg} /$ $\mathrm{dl}$, direct bilirubin of $16.2 \mathrm{mg} / \mathrm{dl}$ [3]. We report a case of congenital CMV presenting on first day of life as conjugated jaundice with total serum bilirubin of $38 \mathrm{mg} / \mathrm{dl}$. We report this case as very few cases have been reported presenting as conjugated hyperbilirubinemia with such high level of serum bilirubin on first day of life and to highlight the role of intravenous ganciclovir in treatment of such patients.

\section{Case Report}

A 20-hours-old male baby of birth weight $3200 \mathrm{gm}$ delivered vaginally to a primigravida mother in a private hospital presented to our hospital for yellowish discoloration of skin, eyes and urine. Antenatal, natal and postnatal periods remained uneventful. Baby started accepting mother's breast feed within 1 hour of birth.

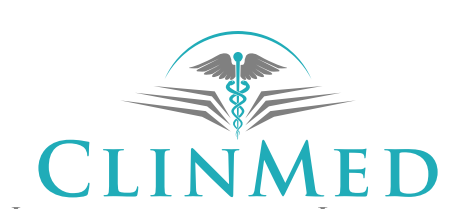

INTERNATIONAL LIBRARY
Citation: Singh A, Sachan R (2018) Congenital Cytomegalovirus Infection Presenting as Severe Conjugated Hyperbilirubinemia on First Day of Life. Int J Pediatr Res 4:035. doi.org/10.23937/2469-5769/1510035 Accepted: July 10, 2018: Published: July 12, 2018

Copyright: (C) 2018 Singh A, et al. This is an open-access article distributed under the terms of the Creative Commons Attribution License, which permits unrestricted use, distribution, and reproduction in any medium, provided the original author and source are credited. 
On examination baby was found to be active and was accepting mother's breast feed very well. Baby had deep icterus up to palms and soles with hepatosplenomegaly (liver $-3 \mathrm{~cm}$ bcm, spleen $2 \mathrm{~cm} \mathrm{bcm}$ ) Serum bilirubin came out to be $38 \mathrm{mg} \%$ with direct component being $15 \mathrm{mg} \%$ and no Rh or ABO incompatibility. Complete blood count was normal with $\mathrm{Hb}-12 \mathrm{gm} \%$, TLC- 9800/ cumm, DLC-P56, L44, platelet- 3.8 lac cu.mm. Peripheral smear revealed no evidence of hemolysis. Direct Coombs test was negative and reticulocyte count was normal. Double-volume exchange transfusion was done on the same day in view of high levels of unconjugated fraction of serum bilirubin. Sepsis screen was negative. Blood culture came out to be sterile. Ultrasonography of abdomen was normal. Blood sugar remained normal throughout hospital stay. Urine reducing sugar was negative. Thyroid profile was normal. Post-exchange transfusion serum bilirubin was $32 \mathrm{mg} \%$, direct component being $8 \mathrm{mg} \%$. TORCH titre report came out to be highly positive for IgM for CMV. Urine PCR for CMV also came out to be positive. Intravenous ganciclovir was started at a dose of $6 \mathrm{mg} / \mathrm{kg} /$ dose every 12 hourly on day 7 of life following which serum bilirubin started falling and became normal in 21 days. Ophthalmic evaluation was negative for chorioretinitis. Cranial USG and BERA were normal. Intravenous ganciclovir was given for 3 weeks with weekly monitoring of blood counts and kidney function tests which remained normal during therapy as shown in Table 1. Neurological examination was normal. So, baby was discharged on 28 days of life on oral valganciclovir in a dose of $6 \mathrm{mg} / \mathrm{kg} /$ dose 12 hourly for next 3 weeks. Baby remained well during follow up with normal serum bilirubin levels, no hepatosplenomegaly, normal fundus examination and normal blood counts. Developmental milestones were normal for age. Brain CECT remained normal with no hydrocephalus and intracranial calcifications. Hearing screen done at 3 and 6 months of age remained normal. Parents were counseled regarding frequent hearing and developmental screening of baby, risk of CMV infection in future pregnancies and also about hygiene to decrease the viral transmission.

\section{Discussion}

Cytomegalovirus is double-stranded DNA virus belonging to Herpesviridae family. Although CMV infection

Table 1: Complete blood count and renal function test during ganciclovir therapy.

\begin{tabular}{|l|l|l|l|l|}
\hline Lab tests & Day 7 & Day 14 & Day 21 & Day 28 \\
\hline CBC: & & & & \\
Hb(gm/dl) & 11.8 & 11.0 & 10.8 & 10.6 \\
\hline TLC(cells/cu.mm) & 12,000 & 11,450 & 13,250 & 11,000 \\
\hline Platelet(cells/cu.mm) & 2.5 & 2.2 & 3.5 & 2.0 \\
\hline RFT: & & & & \\
S. Urea(mg/dl) & 28 & 26 & 24 & 22 \\
\hline S. creatinine(mg/dl) & 0.3 & 0.4 & 0.2 & 0.3 \\
\hline
\end{tabular}

Abbreviations: $\mathrm{CBC}$ : Complete blood count; $\mathrm{Hb}$ : Hemoglobin. can occur in any age group, it remains mostly asymptomatic or mildly symptomatic during infancy, childhood or adulthood. But its presentations may be severe in immunocompromised hosts like neonates either due to congenital infection or due to perinatal infection. When the virus is transmitted transplacentally from mother to fetus due to infection during pregnancy (primary or recurrent) at any gestation, it is called congenital CMV. CMV transmission is more common following primary infection as compared to recurrent infection during pregnancy (30$40 \%$ vs. $1-3 \%$ ) [5-7]. Infection during pregnancy may remain asymptomatic or may present as flu-like illness. Congenital CMV infection affects several body organs like CNS, eyes, GIT, and lungs. It may remain asymptomatic or may manifest as prematurity, low birth weight, chorioretinitis, microcephaly, intracranial calcifications, hydrocephalus, pneumonia, hepatitis, cholestatic jaundice, hepatosplenomegaly, thrombocytopenia or anemia. Congenital CMV infection leads to varied long-term complications in both symptomatic as well as asymptomatic neonates. Although complications occur more frequently in symptomatic cases (40-58\% vs. $13.5 \%$ ) [8]. The most common long-term complication is sensorineural hearing loss (SNHL), others being cerebral palsy, mental retardation, developmental delay, blindness and seizure disorder [9]. Diagnosis of congenital CMV is made by DNA PCR of saliva and urine with or without positive IgM antibody for CMV within 3 weeks of postnatal age [10]. In the present case diagnosis of congenital CMV was established by positive IgM antibody for CMV and isolation of virus by DNA PCR from urine on day 3 of life.

Treatment with injection ganciclovir and oral valganciclovir is indicated in symptomatic cases with CNS involvement and severe end organ involvement like hepatitis, pneumonia and thrombocytopenia. Ganciclovir is given intravenously in a dose of $6 \mathrm{mg} / \mathrm{kg} / \mathrm{dose}$ every 12 hourly for 6 weeks with monitoring of complete blood counts and kidney function test as it is known to cause neutropenia and derangement of renal function transiently. Studies have shown that treatment with IV ganciclovir in symptomatic CMV cases has improved neurodevelopmental outcome in terms of SNHL and developmental delay [10]. But the efficacy of treatment with ganciclovir in non-CNS cases like pneumonia, thrombocytopenia and hepatitis is not established.

The present case had conjugated hyperbilirubinemia with hepatosplenomegaly on first day of life with very high serum bilirubin level. Conjugated jaundice is a wellknown manifestation of congenital CMV but most of the cases present as cholestatic jaundice. Very few cases have been reported with such high serum bilirubin levels on the first day of life. Farehat A, et al. reported conjugated jaundice on first day of life but levels were not high [4]. The baby did not have any other manifestations like chorioretinitis, microcephaly, intracranial calcifications, hydrocephalus, pneumonia, thrombocytopenia or anemia. 
The present case was managed with intravenous ganciclovir with good response in terms of resolution of jaundice and hepatosplenomegaly. Case report by Farehat, et al. and Nazmuddin F, et al. also showed good response to ganciclovir in cases of jaundice due to $\mathrm{CMV}$ $[3,4]$. In the present case ganciclovir was tolerated well with no complications noted during 3 weeks of therapy. The case was followed up for 6 months of life and remained neurodevelopmentally normal.

\section{Conclusion}

Congenital CMV infection may present as conjugated jaundice on the first day of life with high serum bilirubin levels. So, a neonate with such presentation must be evaluated for congenital CMV infection as treatment with ganciclovir and valganciclovir causes not only symptomatic improvement but also prevents long-term neurodevelopmental complications.

\section{Authors Contribution}

Both the authors were involved in patient management and contributed in draft of manuscript.

\section{References}

1. Kenneson A, Cannon MJ (2007) Review and meta-analysis of the epidemiology of congenital cytomegalovirus (CMV) infection. Rev Med Virol 17: 253-276.

2. Stagno S, Britt W (2006) Cytomegalovirus infections. In: Remington J, Klein J, Wilson C, et al., Infectious diseases of the fetus and newborn infant. (6 $6^{\text {th }}$ edn), Elsevier, Philadelphia, 739-781.
3. Najmuddin F, Rai R, George R, Lahiri K (2015) Cytomegalovirus induced neonatal cholestasis: A success story. Ann Pediatr Child Health 3: 1056.

4. Farhat AS, Mohammadzade A, Nourizade S (2015) Firstday direct hyperbilirubinemia in an infant with congenital cytomegalovirus infection. Iranian Journal of Neonatology 6: $56-58$

5. American Academy of Pediatrics (2006) Cytomegalovirus infection. In: Pickering LK, Red book: Report of the committee on infectious disease. (2 $7^{\text {th }}$ edn), American Academy of Pediatrics, Elk Grove Village, IL, 273-277.

6. Nyholm JL, Schleiss MR (2010) Prevention of maternal cytomegalovirus infection: Current status and future prospects. Int J Womens Health 2: 23-35.

7. Cannon MJ, Schmid DS, Hyde TB (2010) Review of cytomegalovirus seroprevalence and demographic characteristics associated with infection. Rev Med Virol 20: 202-213.

8. Dollard SC, Grosse SD, Ross DS (2007) New estimates of the prevalence of neurological and sensory sequelae and mortality associated with congenital cytomegalovirus infection. Rev Med Virol 17: 355-363.

9. Foulon I, Naessens A, Foulon W, Casteels A, Gordts F (2008) Hearing loss in children with congenital Cytomegalovirus infection in relation to the maternal trimester in which the maternal primary infection occurred. Pediatrics 122: e1123-e1127.

10. Kimberlin DW, Lin CY, Sanchez PJ, Demmler GJ, Dankner W, et al. (2003) Effect of ganciclovir therapy on hearing in symptomatic congenital cytomegalovirus disease involving the central nervous system: A randomized, controlled trial. J Pediatr 143: 16-25. 